Document downloaded from:

http://hdl.handle.net/10251/129014

This paper must be cited as:

Morales Torres, A.; Escuder Bueno, I.; Serrano Lombillo, AJ.; Castillo-Rodríguez, J. (2019).

Dealing with epistemic uncertainty in risk-informed decision making for dam safety

management. Reliability Engineering \& System Safety. 191.

https://doi.org/10.1016/j.ress.2019.106562

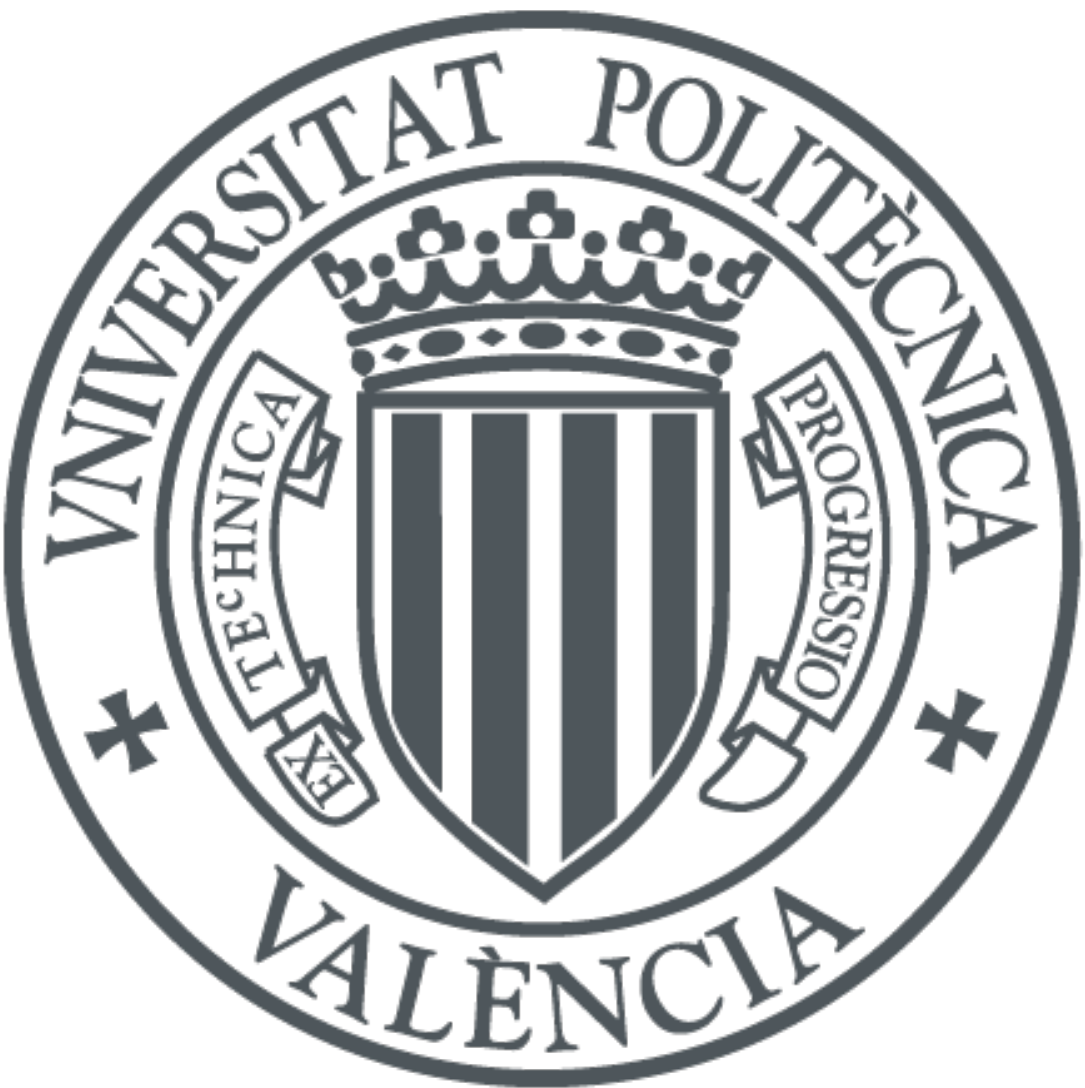

The final publication is available at

http://doi.org/10.1016/j.ress.2019.106562

Copyright Elsevier

Additional Information 


\title{
Dealing with epistemic uncertainty in risk-informed decision making for dam safety management
}

\begin{abstract}
In recent years, the application of risk analysis to inform dam safety governance has increased significantly. In this framework, considering explicitly and independently both natural and epistemic uncertainty in quantitative risk models allows to understand the sources of uncertainty in risk results and to estimate the effect of actions, tests, and surveys to reduce epistemic uncertainty.

In this paper, Indexes of Coincidence are proposed to analyze the effect of epistemic uncertainty in the prioritization of investments based on risk results, which is the key issue in this paper. These indexes allow consideration of the convenience of conducting additional uncertainty reduction actions.

These metrics have been applied to the prioritization of risk reduction measures for four concrete gravity dams in Spain. Results allow for a better understanding of how epistemic uncertainty of geotechnical resistance parameters influence risk-informed decision making.

The proposed indexes are also useful for probabilistic risk analyses of other civil engineering structures with high epistemic uncertainty environments, since they analyze whether existing uncertainty could have an impact on decision making, outlining the need for extra studies, surveys and tests.
\end{abstract}

\section{GRAPHICAL ABSTRACT}

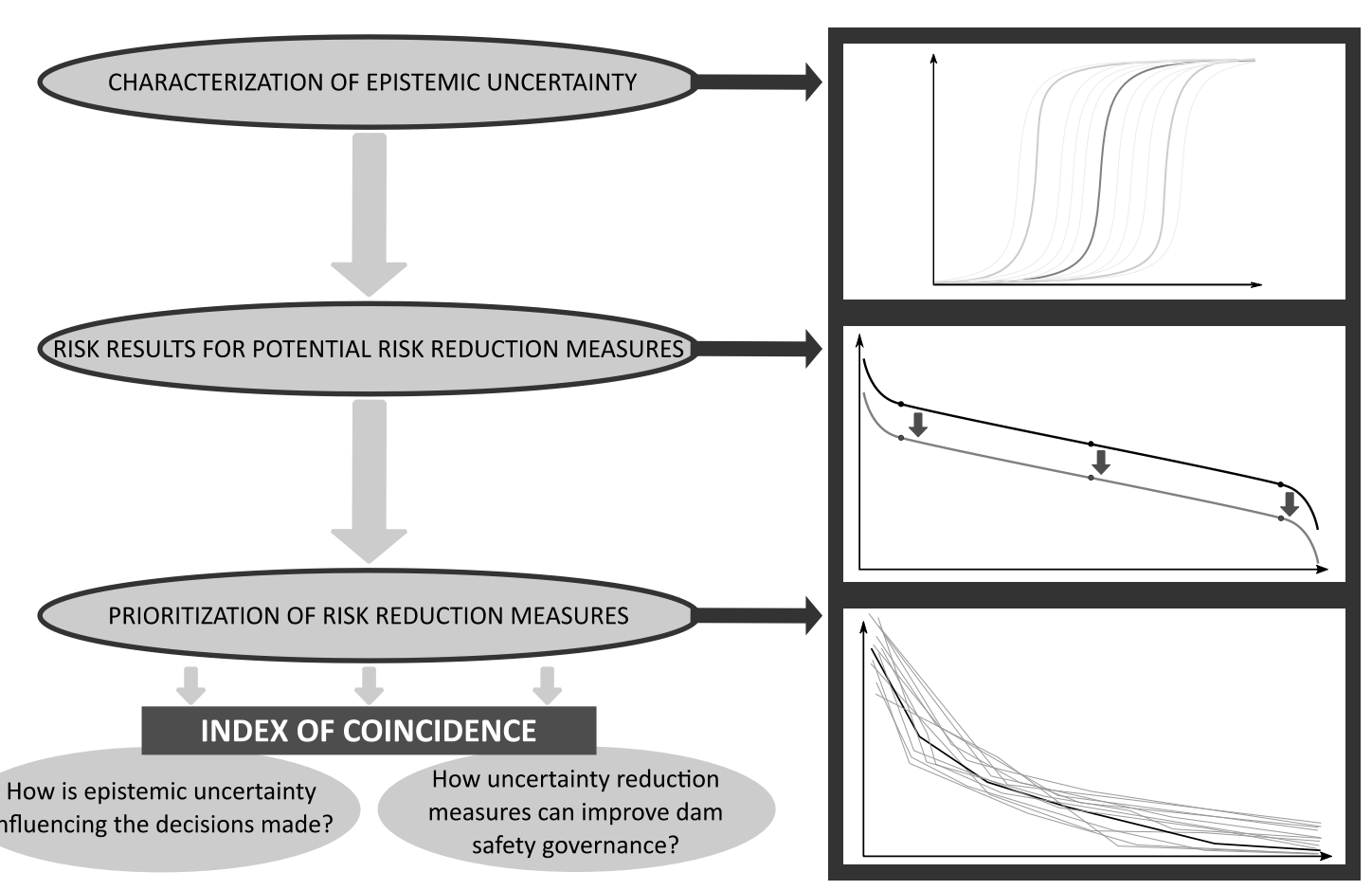




\section{INTRODUCTION}

There is nowadays a trend towards viewing dam safety as an active and ongoing management process rather than a static and deterministic statement. Tools such as risk analysis can be useful to help owners take risk-informed decisions. Risk assessment helps engineers to understand uncertainties in critical infrastructures, and provides a logical process to identify hazards, evaluate system response and vulnerabilities associated to each hazard, and assess the effectiveness of risk reduction measures.

In recent years, risk assessment techniques have been developed and applied in the dam industry worldwide to inform safety governance [1]-[4]. Guidelines and recommendations have been developed within the tolerability of risk (TOR) framework, which was set out by UK's HSE [5] for risk evaluation and management. The current paper is contextualized within this framework.

However, the contextual information provided above is considerably more complex than it may sound, resulting in many theoretical and practical difficulties. Many of these difficulties are related to how uncertainties are explicitly considered today (in the context of risk analysis), as opposed to the more traditional implicit treatment (in the context of state-of-the-art dam safety practice).

Evaluation of uncertainty plays an important role in the evaluation and management of complex structural systems [6], [7]. In general, two sources of uncertainty are considered [8]-[11]:

- Natural uncertainty or randomness: Produced by the inherent variability in natural processes. An example is the variability of the loads that the structure has to withstand, for instance, the variability in the potential flood magnitudes which can occur. This type cannot be reduced, though it can be estimated.

- Epistemic uncertainty: Resulting from not having enough knowledge or information about the analyzed system. This lack of information can be produced by deficiency of data or because the structure's behavior is not correctly represented. The more knowledge that is available about a structure or system, the more this type of uncertainty can be reduced.

Dealing with natural and epistemic uncertainty has been one of the main discussion points in quantitative risk analysis for critical infrastructures safety management. The most common approach is addressing separating both types of uncertainty through a probabilistic analysis [12], obtaining a probabilistic distribution of risk results based on epistemic uncertainty variations. This method was mainly developed within the nuclear industry, thanks to the work made by [13]. It was later generalized by [14] and it is still commonly used in this industry [15]. Other industries which have followed this probabilistic approach to inform safety management are the water supply industry [16], [17] and the aerospace industry [18].

In the dam safety field, epistemic uncertainty has an important role in decision making. Dam managers usually need to decide whether available information (hydrological studies, geotechnical tests, monitoring data...) is sufficient before making an important structural improvement in the dam (new spillway construction, improvement of the foundation resistance, improvement of dam body imperviousness ...). In this sense, analyzing the degree of confidence in risk results and its influence in the decision making process is a key issue for dam safety management. 
In this field, both types of uncertainty are generally introduced in the inputs for dams risk models, without specifically distinguishing the effect of epistemic uncertainty. These results are very useful to prioritize risk reduction investments, but still two key questions for dam safety governance remain unanswered and they are the key for this paper:

- How is epistemic uncertainty influencing the decisions made based on risk results?

- How can potential uncertainty reduction measures (geotechnical tests, dam computational models, improvements in dam surveillance and monitoring...) improve dam safety governance?

In order to answer these questions, this paper provides insights on how addressing separately epistemic uncertainty in risk models (following the approaches already developed in other industries) and presents two indicators named Indexes of Coincidence that measure the effect of epistemic uncertainties in risk-informed decision making. These indexes are computed by analyzing the effect of epistemic uncertainty in prioritization sequences of potential risk reduction measures. These sequences of measures are obtained with the procedure developed in [19].

These Indexes of Coincidence have been obtained to inform safety management in four existing concrete gravity dams in Spain. These real examples illustrate how the proposed Indexes of Coincidence can provide useful information to answer the two previous questions. 


\section{UNCERTAINTY IN RISK MODELS FOR DAMS}

Risk is the combination of three concepts: what can happen, how likely is it to happen, and what are its consequences [20]. Following this definition, in the dam safety field, risk is usually quantified with the following equation [21]:

$$
\text { Risk }=\int P(\text { loads }) \cdot P(\text { response } \mid \text { loads }) \cdot C(\text { loads }, \text { response }) \quad \text { Eq. } 1
$$

where the integral is defined over all the events under study, $P($ loads $)$ is the probability of the different load events, $P$ (response|loads) is the conditional probability of the structural response for each load event and C(loads, response) are the consequences of the system response for each load event. In the dam safety field, the system response analyzed is the dam failure. Consequences can be introduced in economic terms to obtain economic risk or in terms of potential loss of life, to obtain societal risk [19].

These terms of the equation are usually analyzed independently and they can be combined within a quantitative risk model to compute dam failure risk. Risk models are commonly created through event trees [3], [22], which analyze the different ways in which a dam can fail (failure modes) calculating their associated probabilities and consequences. An event tree is a representation of a logical model that includes all the possible chains of events resulting from an initiating event that can produce the structural failure.

In these risk models for dams, natural and epistemic uncertainties are not usually introduced separately. They are usually mixed in the probability input data introduced for the structural response with a mean conditional failure probability for each loading state [23]. Hence, risk curves represent "mean future frequencies" of critical events in the face of epistemic uncertainties. This approach is called first-order probabilistic risk analysis [24] and it is the most common approach in risk-informed dam safety management [2], [3], [22].

As a result of applying Equation 1 in the event tree, a single value of failure probability and risk is obtained. If consequences are expressed in terms of loss of life, FN curves can be derived to represent the relation between loss of life and exceedance probability thanks to the different branches of the event tree. The area under these curves is equivalent to the societal risk [25].

First-order probabilistic risk analysis represents Level 4 of complexity in the classification developed by [26]. There is a higher level of complexity to fully represent both types of uncertainty (Level 5), called second-order probabilistic risk analysis. In this level, epistemic and aleatory uncertainties are introduced separately in the risk model input data, defining probability distributions for input data in the risk equation.

In order to carry out calculations in Level 5 models, the two types of uncertainty can be addressed using a two-loop Monte-Carlo analysis [27]. In the upper loop, random variables with epistemic uncertainty are sampled. These sampled values are used to compute risk in the lower loop. Another option can be to combine epistemic uncertainty variables sampling in the upper loop of Monte-Carlo analysis with event trees. Hence, a risk result is obtained for each group of sampled values with the event tree [28]. In both approaches, when risk results are ordered, a risk probability distribution is obtained. 
Hence, in a second-order probabilistic risk analysis, a risk probability distribution and a family of FN curves are obtained instead of a single value and curve, as explained in [24], [28]. The spread of risk probability distribution and the family of FN curves thus represents the degree of epistemic uncertainty in the risk assessment. In Figure 1, the type of risk results and risk representation are compared for first-order and second-order probabilistic risk analyses. In conclusion, second-order probabilistic risk analysis allows to assess the effect of epistemic uncertainty in risk results and it is more common in other industries like the nuclear industry [14].
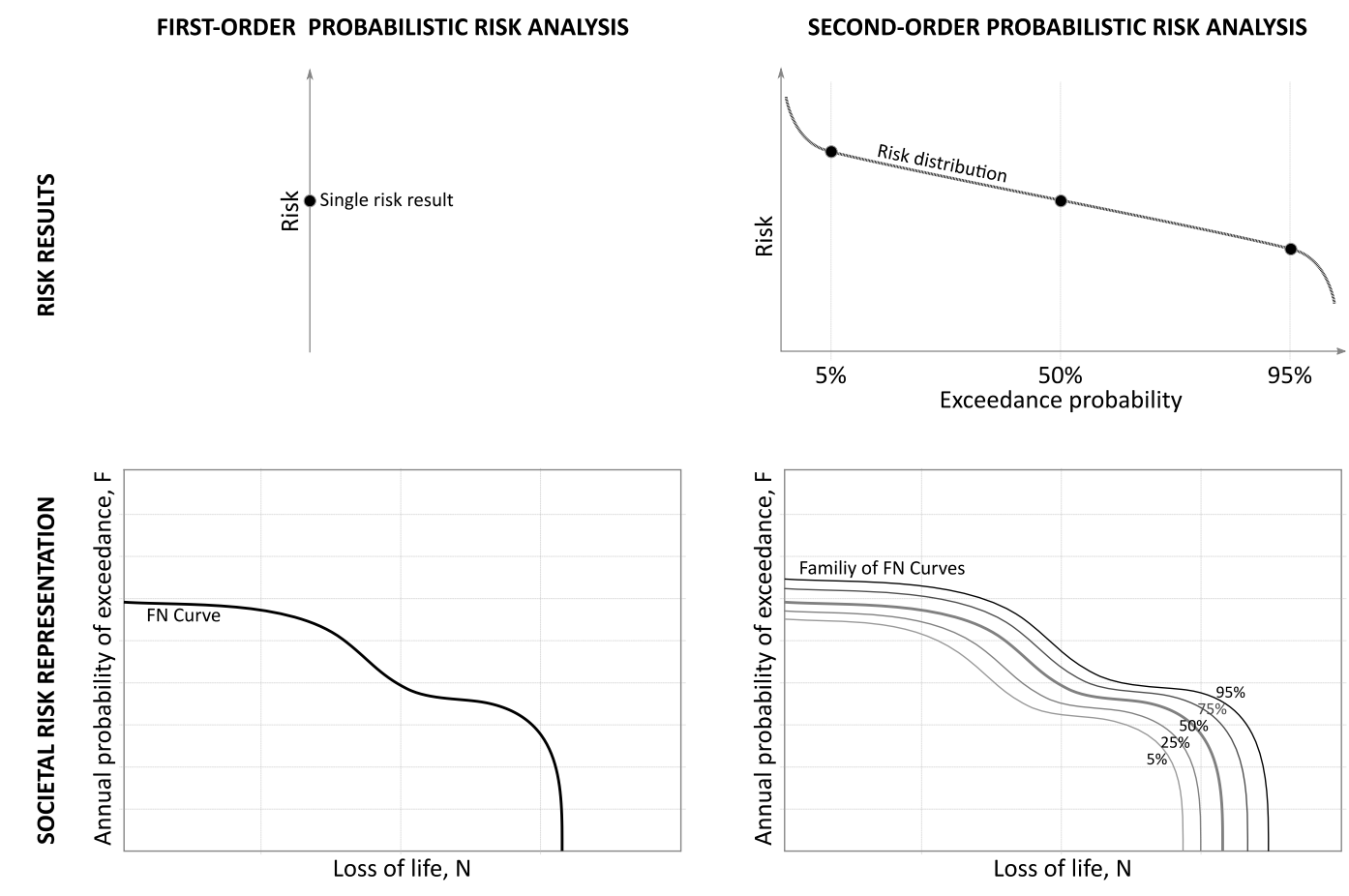

Figure 1: Comparison of risk results and risk representation between first-order and second-order probabilistic risk analysis.

Recent research on dealing with epistemic uncertainty in quantitative risk models for infrastructure management is mainly focused on how epistemic uncertainty is propagated through input data and mathematical models and trees. Methods used to propagate this uncertainty are analytical methods (method of moments and FentonWilkinson method), Monte Carlo simulation, Wilks method and fuzzy set theory [8], [9], [29]-[31]. These methodologies allow to quantify the effect of epistemic uncertainty in risk results to obtain risk distributions, combining different sources of uncertainty in input data.

Other existing approaches that deal with epistemic uncertainty in infrastructure management are based on developing different future scenarios [32]. These approaches are generally used to analyze risks for different investments rather than infrastructures safety management (when potential failure could lead to loss of life, like large dams or nuclear plants). 
In recent years, different research studies have been developed to characterize epistemic uncertainty in input data of quantitative risk analysis of dams. As explained above, the separation of epistemic and aleatory uncertainties in input data is the first step for a second-order risk analysis. Following the three terms of the risk equation (Equation 1), the existing approaches that have been found in the dam safety field to address epistemic uncertainty separately are:

- Probability of loading: This part of the equation typically makes reference to the probability of severe flood events and their subsequent reservoir elevations (hydrological scenario) or severe seismic events (seismic scenario).

In hydrological scenarios, in general a probability distribution for reservoir elevations is introduced in the risk model obtained from the probability of flood events, probability of previous pool levels in the reservoir and probability of availability of outlet works [33], [34].

In order to separate both types of uncertainty, main epistemic uncertainties in the rainfall-runoff and flood routing process should be characterized. Different families of inflow hydrographs in the reservoir can be obtained based on a parametric rainfall-runoff analysis [35] and they can be combine with previous pool levels and gates availability to obtain a family of probability distributions for reservoir elevations (or volumes) in the reservoir [36]. The spread of this family of curves represents the degree of epistemic uncertainty in the hydrological loading.

In seismic scenarios, epistemic and aleatory uncertainties of seismic loading could be separated as it is made in the nuclear industry [14]. Hence, different families of seismic events could be generated to compute failure probability instead of a single Annual Exceedance Probability-Ground acceleration curve [37].

- Probability of system response: This part of the equation is addressed through fragility curves, which represent a relationship between conditional failure probability and the magnitude of loads that produce failure. In [23], a procedure is introduced to perform fragility analysis for dams in order to identify and track natural and epistemic uncertainty separately. This procedure is particularized for the sliding failure mode of concrete gravity dams and it is based on the concepts by [13] to develop seismic fragility curves for the nuclear industry. As a result of this procedure, a family of fragility curves is obtained to characterize the sliding failure, as shown in Figure 2. The spread of this family is an indicator of the influence of the epistemic uncertainty in the results. 


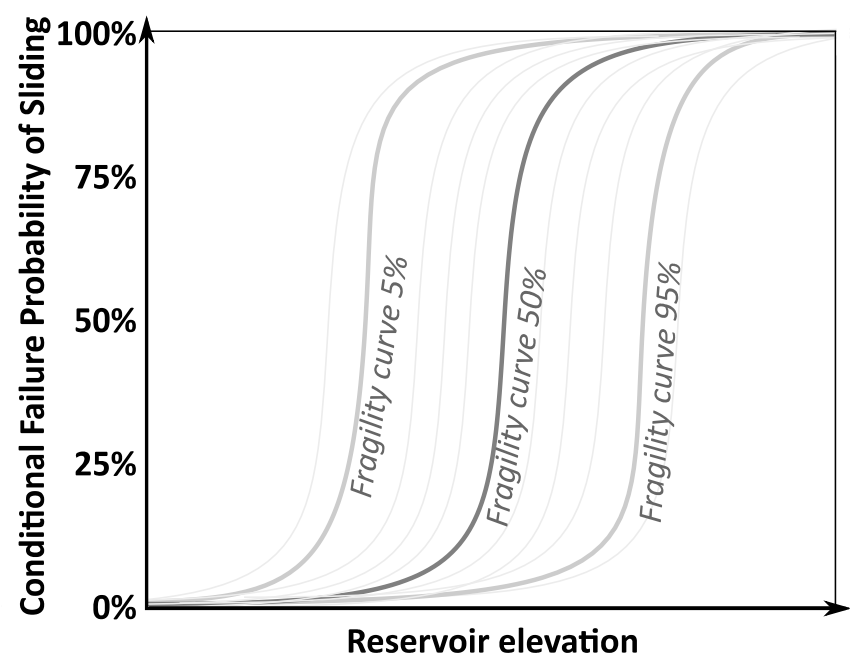

Figure 2: Example of family of fragility curves for sliding failure mode. Adapted from [23].

The same concepts can be followed to obtain a family of fragility curves for other failure modes in dams, like embankment instability [38] and overtopping [37].

Dam failure consequences: In first-order probabilistic risk analysis, a single value of economic consequences or loss of life is used in each branch of the event tree to compute risk. In order to include epistemic uncertainty, a probability distribution of consequences could be introduced. These probability distributions can be obtained based on epistemic uncertainties in hydraulic models [39] and warning and evacuation procedures [37], [40]. 


\section{RISK-INFORMED DECISION MAKING FOR DAM SAFETY MANAGEMENT}

Once risk results are computed, they are used to inform dam safety management. In general, risk analysis to inform dam safety governance is contextualized within the Tolerability of Risk (TOR) framework developed by [5] for risk evaluation and management. This framework has been used worldwide to define risk-informed dam safety programs [2]-[4], [41]. According to this framework, two basic principles are generally used to guide decision making [1], [5]: Equity (based on the premise that all individuals have unconditional rights to certain levels of protection) and Efficiency (which prioritizes options that produce a higher risk reduction at a lower cost).

When quantitative risk analysis is applied to inform safety management of portfolios of dams, a high number of results are obtained. In this context, risk reduction indicators have proved to be a useful tool to prioritize risk reduction measures. These indicators are numeric values obtained for each potential risk reduction measure considered based on its costs and the quantitative risk reduction it provides (using a first-order probabilistic risk analysis).

In [19], a procedure to obtain prioritization sequences based on risk reduction indicators is introduced. In each step of the sequence, the measure with the lowest value of the indicator is chosen. The obtained prioritization sequence depends on the risk reduction indicator used to define it. Prioritization sequences can be represented in variation curves (Figure 3), which represent the variation of the aggregated risk in the portfolio as measures are implemented. In the $X$ axis, annualized costs or implementation steps can be displayed while in the $\mathrm{Y}$ axis aggregated individual risk, societal risk or economic risk can be shown. Depending on what is represented in each axis, the risk reduction indicator that will lead to the optimum sequence is different.

Existing risk reduction indicators to compare different investment alternatives are reviewed in [19], analyzing the relation between risk reduction measures and equity and efficiency principles. In dam safety management, two indicators are predominant in the evaluation of risk reduction measures:

- CSLS (Cost per Statistical Life Saved): [2], [5] This indicator shows how much it costs to avoid each potential loss of life as a result of a dam failure. Its value is obtained through the following formula:

$$
C S L S=\frac{C_{a}}{r_{S}(\text { base })-r_{S}(m e a)}
$$

Where $r_{s}$ (base) is the risk expressed in loss of lives for the base case, $r_{s}($ mea $)$ is the risk in lives after the implementation of the measure and $C_{a}$ is the annualized cost of the measure including its annualized implementation costs, annual maintenance costs and potential changes in operation costs produced by the adoption of the measure. CSLS compares costs with societal risk reduction, so it is directly related with the principle of efficiency.

- ACSLS (Adjusted Cost per Statistical Life Saved): [2] This indicator has the same structure as CSLS but introduces an adjustment of the annualized cost to consider the economic risk reduction generated by the implementation of the measure. It is obtained with the following equation: 


$$
A C S L S=\frac{C_{a}-\left(r_{e}(\text { base })-r_{e}(\text { mea })\right)}{r_{S}(\text { base })-r_{S}(\text { mea })}
$$

Where $r_{e}$ (base) is the economic risk of the infrastructure for the base case and $r_{e}$ (mea) is the economic risk after the implementation of the measure. It is also based on the efficiency principle.

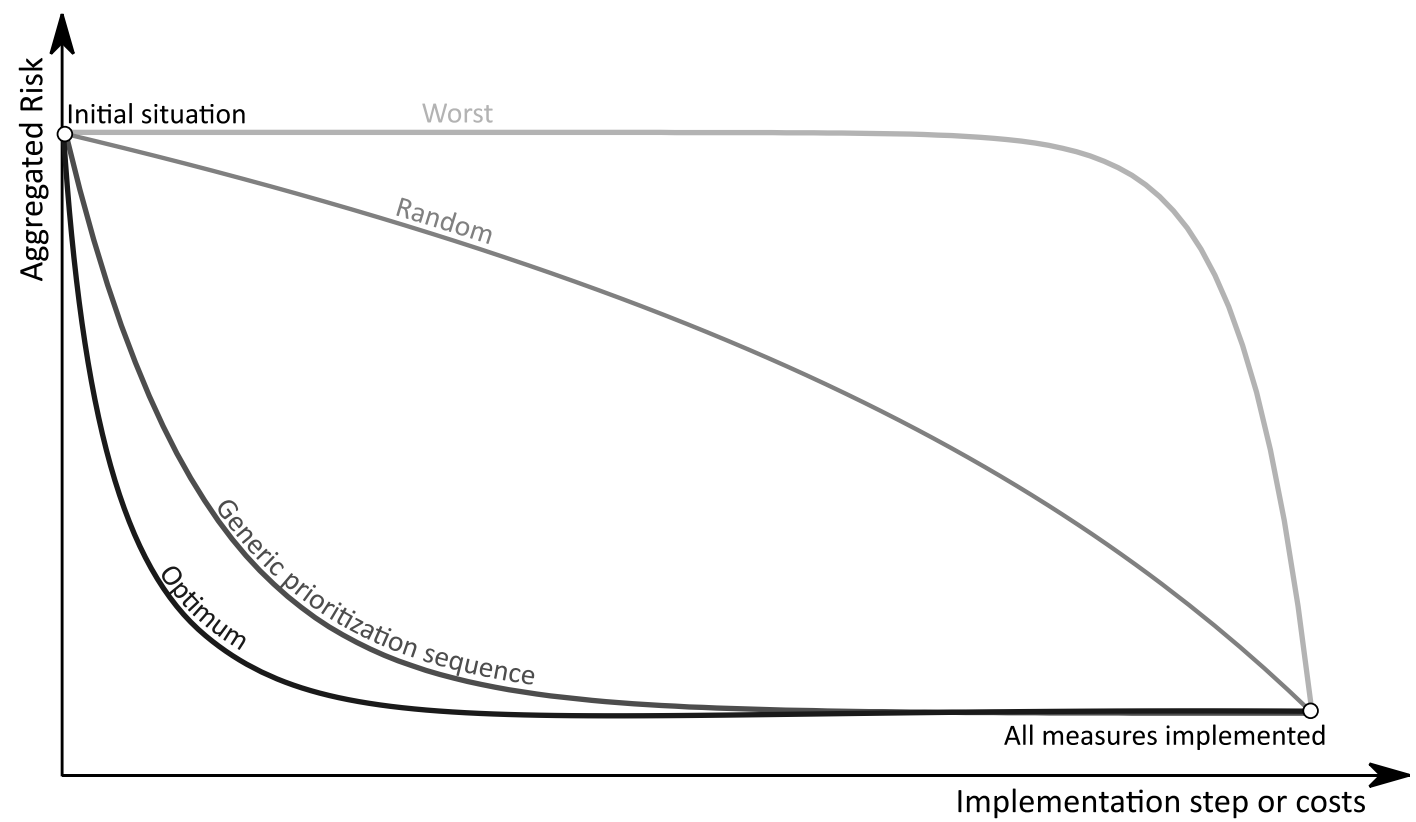

Figure 3: Generic representation of variation curves to define prioritization sequences. Source: [42].

Finally, in [42] a new risk reduction indicator is introduced to combine equity and efficiency principles: Equity Weighted Adjusted Cost per Statistical Life Saved (EWACSLS). This indicator is computed with the following formula:

$$
E W A C S L S=\frac{A C S L S}{\left(\frac{\max \left(r_{i}(\text { base }), I R L\right)}{\max \left(r_{i}(\text { mea }), I R L\right)}\right)^{n}}
$$

Where $r_{i}$ (base) is the individual risk for the base case expressed in years ${ }^{-1}, r_{i}(m e a)$ is the individual risk in years ${ }^{-1}$ after the implementation of the measure, IRL stands for Individual Risk Tolerability Limit and $n$ is a parameter that allows assigning a higher weight to either efficiency or equity in the prioritization process. As can be observed in Equation 4, if the individual risk is lower than IRL, the only prevailing principle is efficiency (through ACSLS), since the denominator of the formula is then 1. Thus, the equity principle only modifies the value of the indicator in the cases where individual risk is above tolerability thresholds.

In conclusion, risk reduction indicators are a useful tool to prioritize a high number of investments in a portfolio of dams based on quantitative risk results. However, this approach does not consider the effect of epistemic uncertainty in risk results separately. 
For this reason, these prioritization sequences are focused on risk reduction measures but they do not address the potential epistemic uncertainty reduction measures (better hydrological studies, more geotechnical tests, improved analysis of dam behavior...), which are also a key part of dam safety management. 


\section{INDEXES OF COINCIDENCE TO ANALIZE EPISTEMIC UNCERTAINTY IN DAM SAFETY DECISION MAKING}

In dam safety management, two types of investments can be analyzed: risk reduction measures (higher outlets capacity, freeboard requirements...) and uncertainty reduction measures (geotechnical tests, dam computational models...). These two types of measures have a different impact on a risk probability distribution obtained by a secondorder probability risk assessment. Risk reduction measures move the probability distribution downwards, while measures to reduce epistemic uncertainty produce a less steep risk distribution, as shown in Figure 4.

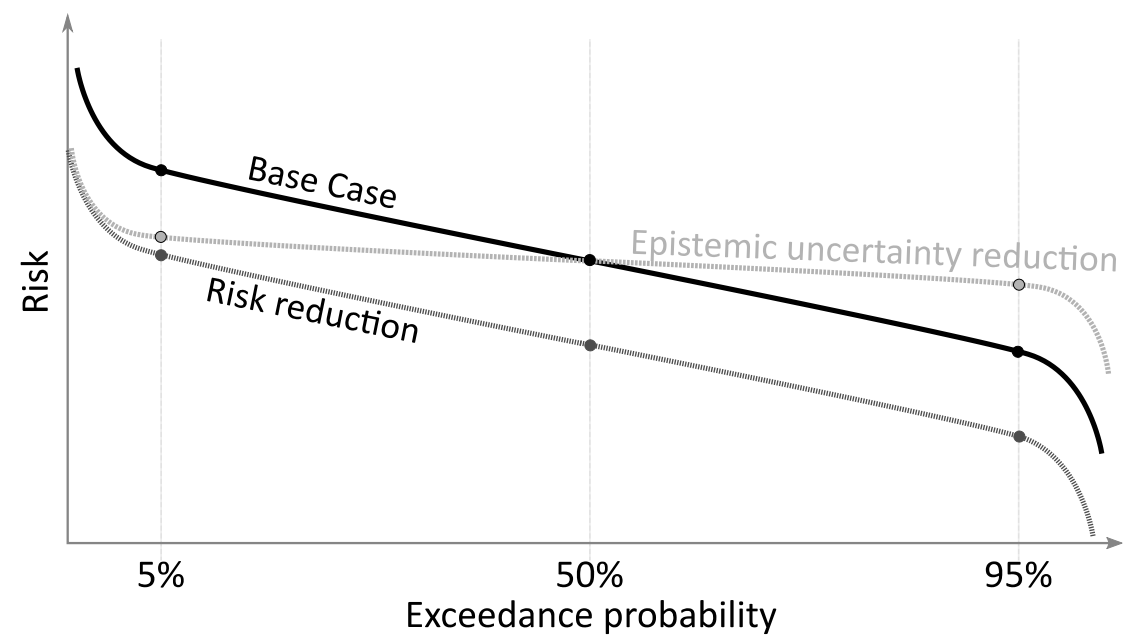

Figure 4: Example of the effect in a risk distribution of a risk reduction measure and an epistemic uncertainty reduction measure.

As explained in Section 3, current approaches to inform dam safety are focused on average risk results from first-order probabilistic risk analysis. For this reason, they are used to prioritize risk reduction measures but they do not analyze the effect of epistemic uncertainty. However, this type of uncertainty can influence decision making and prioritization sequences. In high epistemic uncertainty situations, the decisions made can change depending on the values considered within the epistemic uncertainty distributions, since existing epistemic uncertainty produces a range of variation in risk results, thus when different dams are compared, this variation could lead to different results on which remedial measures are more efficient.

As explained in Section 2, in a second-order probabilistic risk analysis a high number of risk results are obtained instead of a single risk value. This difference between the results of a first-order and second-order probabilistic risk analysis can be observed in Figure 1. The spread of these results obtained in a second-order probabilistic risk analysis indicates the existing epistemic uncertainty. Hence, in this type of analysis a high number of risk results are obtained for the base case and for each risk reduction measure analyzed.

When these results are combined with the calculation of prioritization sequences explained in Section 3, a high number of sequences are obtained for each risk reduction indicator, instead of a single sequence for the average values. The differences between these high number of sequences indicate how epistemic uncertainty influences decision making. In a case where epistemic uncertainty is not influential, the order of the analyzed measures in all the sequences will be the same, while in a case with a high 
influence of epistemic uncertainty, there will be higher differences in the order of measures within the sequences. According to the authors, this is the key of dealing with epistemic uncertainty within dam safety management: analyzing how it can change the decisions made and when it is recommended to invest in reducing this type of uncertainty.

Based on this reasoning, two different indexes have been developed and proposed in this paper to measure the effect of epistemic uncertainty in the calculation of prioritization sequences. These metrics are based on the difference in the order of measures between each sequence obtained with the results of a second-order probabilistic risk analysis and the reference sequence obtained with the average values from first-order risk analysis. The two indexes developed are:

- Index of Coincidence (IC): It quantifies the difference in the order of measures between two sequences. It is computed with the following equation:

$$
I C=\left(\sum_{i=1}^{N} 1-\frac{\left|p r_{i}-p_{i}\right|}{\max \left(p r_{i}-1, N-p r_{i}\right)}\right) / N
$$

Where $N$ is the number of measures in the sequences compared, $p r_{i}$ is the position of the measure $i$ in the reference sequence and $p_{i}$ is the position of the measure $i$ in the sequence compared with the reference sequence.

Figure 5 graphically shows how this indicator is computed in an example. For each step of the measure, it is computed with the division of the difference in the position of a sequence in the two itineraries (A in this figure) and the maximum difference in the position that there could be ( $\mathrm{B}$ in this figure).

- Adjusted Index of Coincidence (AIC): It is computed multiplying the Index of Coincidence in each step by a factor to preponderate the first measures of the sequence, since they are more important in the decision making process. This adjustment factor varies from 2 for the first step of the measure to 0 for the last step. It can be computed with the following equation:

$$
A I C=\left(\sum_{i=1}^{N} I C_{i} \cdot \frac{2 \cdot\left(N_{i}-p_{i}\right)}{N-1}\right) /_{N}
$$

Where $I C_{i}$ is the partial Index of Coincidence for measure $i$ in the sequence, obtained with equation 5 .

Table 1 illustrates how these two indexes are calculated for the example shown in Figure 5. In this table, $A I C_{i}$ are the partial Adjusted Index of Coincidence for each step of the sequence, obtained with equation 6. The name of Index of Coincidence has been chosen based on the Index of Coincidence used in cryptography to analyze the similarity between two texts [43].

Thus, these indexes of coincidence can be used to compare each implementation sequence obtained through a second-order probabilistic risk analysis with the reference implementation sequence obtained with a first-order probabilistic risk analysis. Hence, a high number of Indexes of Coincidence are obtained, one for each sequence. The average Index of Coincidence of all these sequences is an indicator on how epistemic uncertainty is influencing decision making, since it indicates the differences in the order of measures that epistemic uncertainty could produce. 
With this approach, results of first-order probabilistic risk analysis can be used to define the reference prioritization sequence for risk reduction measures, while average Index of Coincidence indicate the influence of epistemic uncertainty and the need for uncertainty reduction measures. In this sense, the proposed metrics are not used to obtain new sequences of prioritization sequences as explained in Section 3, but rather to analyze how epistemic uncertainty could change the order of measures in the obtained sequences.

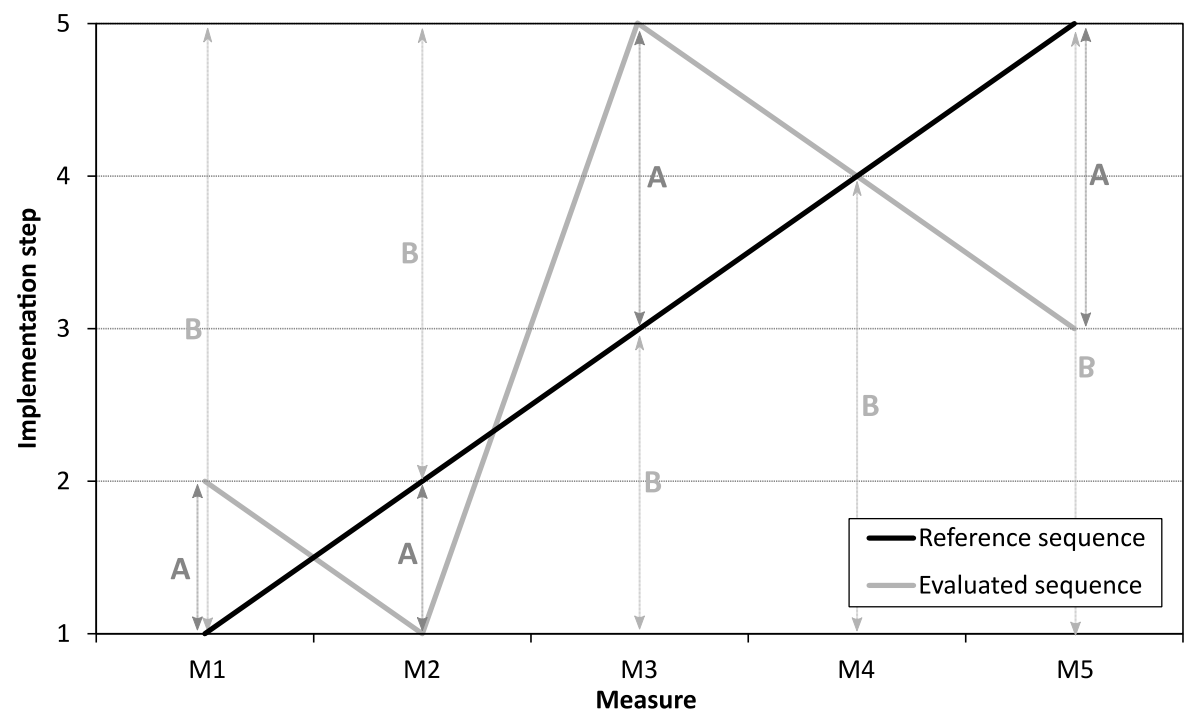

Figure 5: Graphical representation of Index of Coincidence to compare two prioritization sequences.

\begin{tabular}{|c|c|c|c|c|c|c|c|}
\hline Measure & $p_{i}$ & $p r_{i}$ & $\begin{array}{c}\text { Difference } \\
\text { between } \\
\text { itineraries } \\
\text { (A) }\end{array}$ & $\begin{array}{c}\text { Maximum } \\
\text { possible } \\
\text { difference } \\
(B) \\
\end{array}$ & $I C_{i}$ & $\begin{array}{l}\text { Adjustment } \\
\text { factor }\end{array}$ & $A I C_{i}$ \\
\hline M1 & 2 & 1 & 1 & 4 & $75 \%$ & 2 & $150 \%$ \\
\hline M2 & 1 & 2 & 1 & 3 & $67 \%$ & 1.5 & $100 \%$ \\
\hline M3 & 3 & 3 & 2 & 2 & $0 \%$ & 1 & $0 \%$ \\
\hline M4 & 4 & 4 & 0 & 3 & $100 \%$ & 0.5 & $50 \%$ \\
\hline M5 & 5 & 5 & 2 & 4 & $50 \%$ & 0 & $0 \%$ \\
\hline \multicolumn{3}{|c|}{ Index of Coincidence } & & & $\mathbf{5 8 \%}$ & & \\
\hline \multicolumn{3}{|c|}{ Adjusted Index of Coincidence } & & & & & $60 \%$ \\
\hline
\end{tabular}

Table 1: Example of calculation of Indexes of Coincidence to compare two prioritization sequences with five measures.

Although the average Index of Coincidence can be computed when epistemic uncertainty is introduced in the three parts of the risk equation, as explained in Section 3 , they may be more useful when they are computed after introducing epistemic uncertainty in just one part of the input data.

With this purpose, the main sources of epistemic uncertainty in the risk model can be identified and their average Indexes of Coincidence can be independently computed to identify the sources of epistemic uncertainty that have a higher influence in the decision 
making. According to the authors' experience, Table 2 shows reference values of average Indexes of Coincidence and what they could indicate when they are computed for a single source of uncertainty in the risk model. These values are based on the authors experience and they are a first guidance to interpret these indexes, although the interpretation of the Index of Coincidences and the sources of uncertainty should be analyzed in each case.

\begin{tabular}{cc}
\hline $\begin{array}{c}\text { Average Index of } \\
\text { Coincidence value }\end{array}$ & $\begin{array}{c}\text { Degree of influence of this source of epistemic } \\
\text { uncertainty in measures prioritization }\end{array}$ \\
\hline$>\mathbf{9 9 \%}$ & Low \\
$\mathbf{9 5 \%}-\mathbf{9 9 \%}$ & Low-Medium \\
$\mathbf{9 5 \%}-\mathbf{8 5 \%}$ & Medium \\
$\mathbf{8 5 \%}-\mathbf{7 5 \%}$ & Medium-High \\
$\mathbf{7 5 \%}-\mathbf{6 0 \%}$ & High \\
$<\mathbf{6 0 \%}$ & Efforts should be focused on reducing epistemic \\
\hline
\end{tabular}

Table 2: Indicative meaning of average Index of Coincidence when computed for a single source of epistemic uncertainty.

Therefore, Indexes of Coincidence indicate the need for epistemic uncertainty reduction measures, so they are very useful for risk-informed dam safety management. In this sense, the effect of epistemic uncertainty reduction measures in the probability distributions introduced in the risk model can be estimated and Indexes of Coincidence can be recomputed. Expected increments in average Indexes of Coincidence of more than $5 \%$ indicate effective uncertainty reduction measures, especially when Indexes of Coincidence are lower than $85 \%$.

In summary, the general procedure to obtain these sequences in the prioritization of risk reduction actions for a portfolio of dams is:

1. Analysis of main epistemic uncertainty sources in each dam to introduce them separately in a probabilistic risk model.

2. Computation of risk distributions for each dam through a second-order probabilistic risk analysis.

3. Quantification on how proposed risk reduction actions in each dam change the risk results obtained.

4. Computation of a high number of prioritization sequences of risk reduction actions in the portfolio based on risk results.

5. Estimation of indexes of coincidence and analysis on how epistemic uncertainty is changing decision making.

For this reason, these metrics go a step further than existing approaches to deal with epistemic uncertainty. As explained in Section 2, these approaches are mainly focused on analyzing how uncertainty is propagated through risk models and results (Steps 1-3), while indexes of coincidence analyze how these variations in risk results may influence prioritization sequences of risk reduction actions. Therefore, they are more focused on the effects of epistemic uncertainty in practical decision making.

\section{CASE STUDY}


In this section, the approach introduced in this paper is applied to inform safety management in four existing concrete gravity dams in Spain. Main characteristics of these dams are summarized in Table 3. As can be observed, it is a heterogeneous group of concrete gravity dams in size and age.

\begin{tabular}{cccccc}
\hline Dam & Height (m) & $\begin{array}{c}\text { Reservoir } \\
\text { volume }\left(\mathbf{h m}^{\mathbf{3}}\right)\end{array}$ & $\begin{array}{c}\text { Upstream } \\
\text { slope }\end{array}$ & $\begin{array}{c}\text { Downstream } \\
\text { slope }\end{array}$ & $\begin{array}{c}\text { Construction } \\
\text { year }\end{array}$ \\
\hline A & 91.2 & 308 & 0.05 & 0.76 & 1956 \\
B & 31.5 & 0.3 & 0.15 & 0.7 & 1991 \\
C & 58 & 496 & 0 & 0.767 & 1960 \\
D & 59.5 & 24.4 & 0.05 & 0.76 & 1954 \\
\hline
\end{tabular}

Table 3: Main characteristics of case study dams.

The starting point for this case study is the risk models elaborated within a first-order probabilistic risk analysis performed on each dam. The analysis made is focused on the potential sliding of these dams and the epistemic uncertainty about the foundation resistant capacity. This failure mode is analyzed since sliding produced by insufficient shear strength in the foundation is the most common cause of failure of concrete gravity dams according to the International Commission on Large Dams [44]. Hence, the analysis introduced in this case study is focused on this source of epistemic uncertainty within the risk model and how it can influence decision making.

Sliding safety management in these dams deals with the prioritization of potential risk reduction measures and/or investing in reducing uncertainty about the foundation. A total number of 20 potential risk reduction measures (summarized in Table 4) have been analyzed in the four analyzed dams. These structural and non-structural measures came from a list of actions already planned by the operators to improve dam safety along with the needs revealed by the results of the risk analysis process.

\begin{tabular}{|c|c|c|c|}
\hline Dam & Risk reduction measures & Dam & Risk reduction measures \\
\hline \multirow{5}{*}{$\mathbf{A}$} & 1. Improve spillway gates reliability & \multirow{5}{*}{$\mathbf{C}$} & 1. Improve foundation conditions \\
\hline & 2. Emergency Action Plan & & 2. Emergency Action Plan \\
\hline & $\begin{array}{l}\text { 3. Improve reliability of intermediate } \\
\text { outlet gates }\end{array}$ & & 3. Improve reliability of spillway gates \\
\hline & $\begin{array}{l}\text { 4. Injections to improve foundation } \\
\text { conditions }\end{array}$ & & 4. Improve monitoring system \\
\hline & $\begin{array}{l}\text { 5. New piezometers to measure uplift } \\
\text { pressures }\end{array}$ & & 5. New freeboard requirements \\
\hline \multirow{5}{*}{ B } & 1. Improve drainage system & \multirow{5}{*}{$\mathbf{D}$} & 1. Improve dam access \\
\hline & 2. Emergency Action Plan & & 2. Emergency Action Plan \\
\hline & $\begin{array}{l}\text { 3. Improve reliability of bottom outlet } \\
\text { gates }\end{array}$ & & 3. Improve drainage system \\
\hline & 4. Increase spillway capacity & & 4. Improve monitoring system \\
\hline & 5. Improve monitoring system & & 5. Remote control for spillway gates \\
\hline
\end{tabular}

Table 4: Analyzed risk reduction measures analyzed for case study dams.

Firstly, in order to introduce epistemic uncertainty within the risk models for this failure mode, the procedure described in [23] is followed to obtain a family of fragility curves. The purpose of this case study is not to illustrate this method, but to use its results to compute the metrics proposed in this paper. In this case, since the uncertainty on the foundation resistance capacity is the main concern for the sliding failure modes in these 
dams, two independent random variables are considered within a Limit Equilibrium Model: friction angle and cohesion. For each dam, two probabilistic distributions have been estimated for both random variables as shown in Table 5. The estimation of these probabilistic distributions by expert judgement is a complex process which is out of the scope of this paper and it should be based on appropriate empirical data and analyses, such us geotechnical in-situ and laboratory tests, and their temporal and spatial variations. Changes in these distributions would also produce changes in the risk results and could potentially modify Indexes of Coincidence. Differences in standard deviation of epistemic uncertainty distributions between the dams indicate different levels of knowledge about the foundation.

\begin{tabular}{|c|c|c|c|c|c|}
\hline Random variable & Mean & St. Deviation & Maximum & Minimum & Type \\
\hline \multicolumn{6}{|c|}{ DAM A - Highest dam in general good conditions } \\
\hline \multicolumn{6}{|c|}{ Natural uncertainty } \\
\hline Friction angle $\left(^{\circ}\right)$ & 50 & 5 & 65 & 35 & Normal \\
\hline Cohesion (MPa) & 0.5 & 0.2 & 1.5 & 0.1 & Log-Normal \\
\hline \multicolumn{6}{|c|}{ Epistemic uncertainty } \\
\hline Mean friction angle $\left(^{\circ}\right)$ & 50 & 2.5 & 60 & 40 & Normal \\
\hline Mean cohesion $(\mathrm{MPa})$ & 0.5 & 0.125 & 1 & 0.2 & Log-Normal \\
\hline \multicolumn{6}{|c|}{ DAM B - Dam with higher epistemic uncertainty in geotechnical parameters } \\
\hline \multicolumn{6}{|c|}{ Natural uncertainty } \\
\hline Friction angle $\left({ }^{\circ}\right)$ & 42.3 & 4.1 & 53.5 & 31.3 & Normal \\
\hline Cohesion (MPa) & 0.41 & 0.083 & 0.89 & 0.11 & Log-Normal \\
\hline \multicolumn{6}{|c|}{ Epistemic uncertainty } \\
\hline Mean friction angle $\left(^{\circ}\right)$ & 42.3 & 10.8 & 53.5 & 31.3 & Normal \\
\hline Mean cohesion $(\mathrm{MPa})$ & 0.41 & 0.187 & 0.89 & 0.11 & Log-Normal \\
\hline \multicolumn{6}{|c|}{ DAM C - Dam with the largest reservoir } \\
\hline \multicolumn{6}{|c|}{ Natural uncertainty } \\
\hline Friction angle $\left({ }^{\circ}\right)$ & 42 & 4.2 & 54 & 30 & Normal \\
\hline Cohesion (MPa) & 0.3 & 0.12 & 1 & 0.05 & Log-Normal \\
\hline \multicolumn{6}{|c|}{ Epistemic uncertainty } \\
\hline Mean friction angle $\left({ }^{\circ}\right)$ & 42 & 2.1 & 49 & 35 & Normal \\
\hline Mean cohesion (MPa) & 0.3 & 0.105 & 0.8 & 0.1 & Log-Normal \\
\hline \multicolumn{6}{|c|}{ DAM D - Dam with lower epistemic uncertainty about foundation behavior } \\
\hline \multicolumn{6}{|c|}{ Natural uncertainty } \\
\hline Friction angle $\left({ }^{\circ}\right)$ & 40 & 4 & 50 & 30 & Normal \\
\hline Cohesion (MPa) & 0.2 & 0.08 & 0.8 & 0.03 & Log-Normal \\
\hline \multicolumn{6}{|c|}{ Epistemic uncertainty } \\
\hline Mean friction angle $\left(^{\circ}\right)$ & 40 & 2 & 45 & 35 & Normal \\
\hline Mean cohesion (MPa) & 0.2 & 0.07 & 0.5 & 0.05 & Log-Normal \\
\hline
\end{tabular}

Table 5: Probability distribution considered for the random variables to obtain the family of fragility curves.

Following the procedure detailed in [23], a family of 1000 fragility curves has been obtained for each dam. For instance, Figure 6 shows the family of fragility curves obtained for dam A. As explained in Section 2, the spread of this family is an indicator of the influence of the epistemic uncertainty in system-response results. 


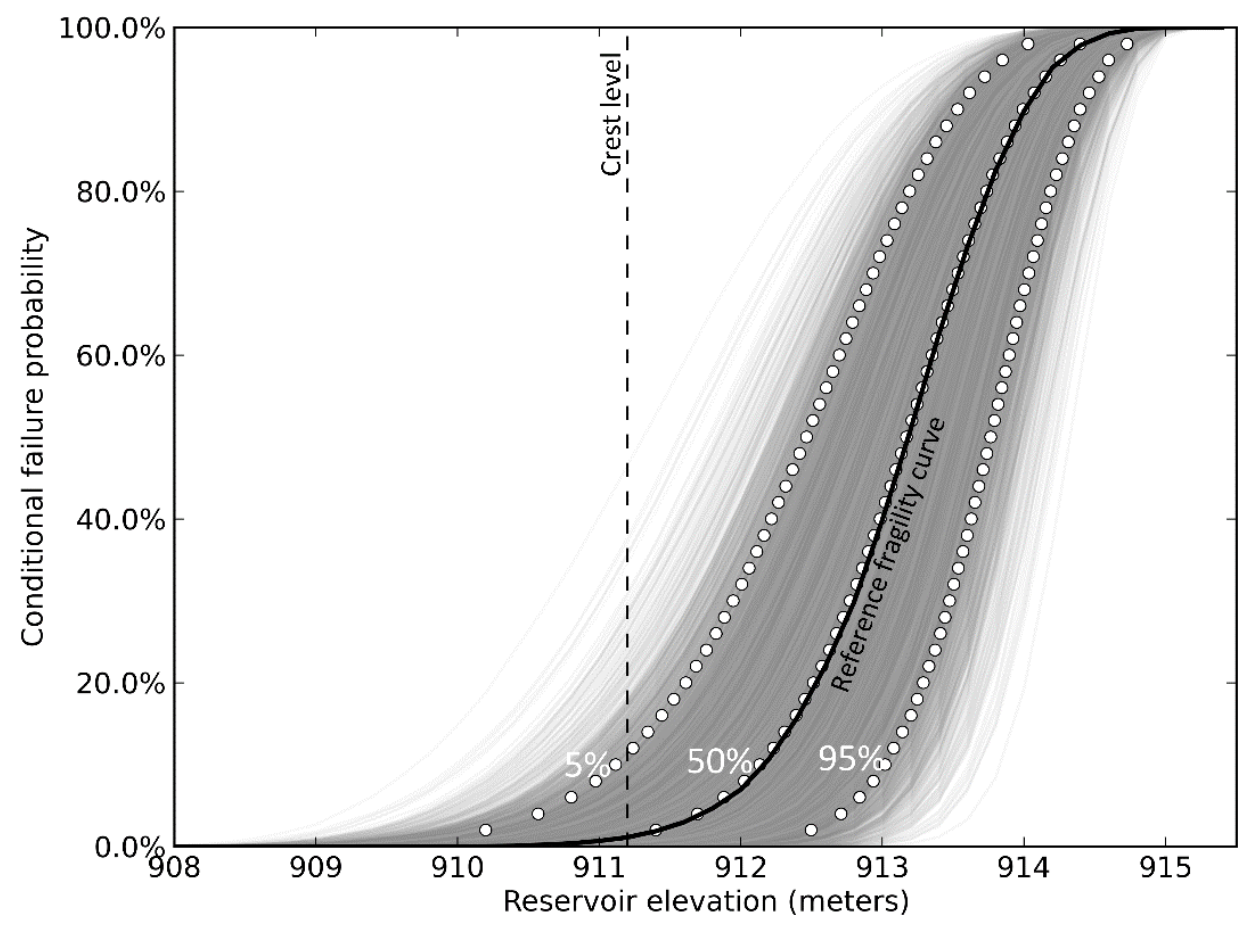

Figure 6: Family of fragility curves obtained for Dam A.

Secondly, the family of fragility curves has been introduced in the quantitative risk model elaborated for each dam in order to obtain a risk probability distribution for sliding failure. These risk models have been elaborated using iPresas Calc software [45], which is based on event trees to compute failure probability and risk. For instance, Figure 7 shows the risk model structure for Dam A. The risk model architecture of the four risk models is very similar. These risk models have been used to compute risk for the current situation and for the 20 risk reduction measures analyzed.

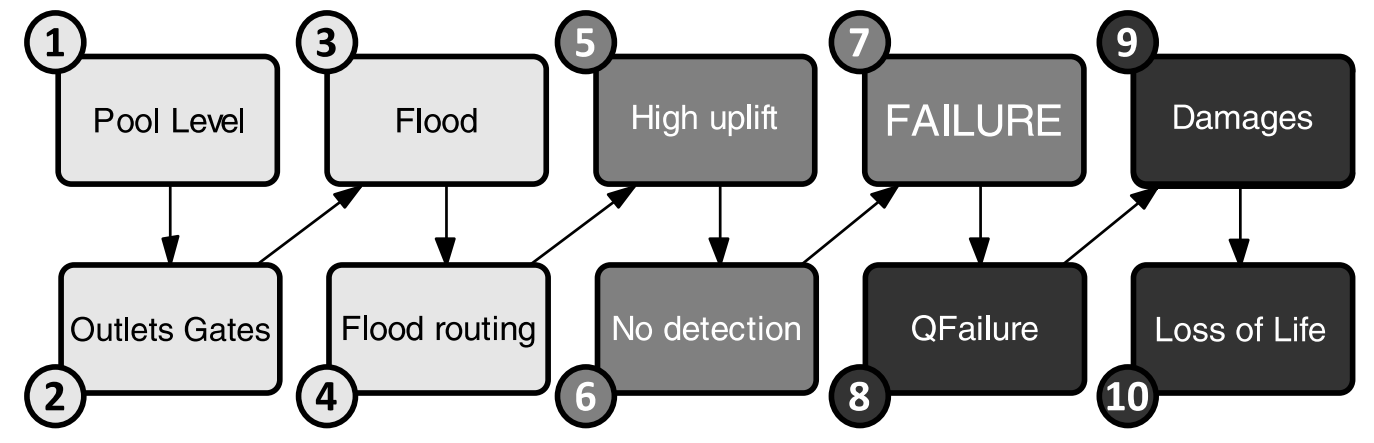

Figure 7: Risk model structure for Dam A.

In the first four nodes (nodes 1-4), this model creates an event tree with 144 branches to compute the probability of different flood routing scenarios in the reservoir (for different flood events, different previous pool levels in the reservoir and different cases of spillway gates availability) in order to obtain an annual exceedance probability curve of the water pool level in the reservoir. Detailed procedures followed to compute this input data are explained in [34].

Nodes 5 and 6 are different for each dam and they estimate the probability of being in different uplift pressures hypothesis, following the sliding numerical model. 
Probabilities introduced in these nodes are based on foundation characteristics, available information about uplift pressures and existing capacity to detect and to avoid high uplift pressures.

Node 7 is used to incorporate the sliding fragility curves in order to relate the maximum water level reached in the reservoir in each flood event with the conditional failure probability. The failure probability of each branch of the event tree is computed multiplying the probabilities of all the nodes. Consequently, when the probabilities of all the branches of this event tree are added, the dam failure probability due to sliding is obtained.

Nodes 8-10 are used to compute consequences in order to estimate risk, following equation 1 . Node 8 is used to introduce a relation between the water pool level and the peak failure discharge. This relation has been previously computed using hydraulic models of the dam breach. Finally, Nodes 9 and 10 introduce the relation between failure discharge and loss of life and economic consequences due to failure. These consequences for different discharges have also been computed using a hydraulic model of the dam break flood. Detailed procedures followed to derive consequences input data are explained in [46].

For each curve of the family of fragility curves of each dam, these risk models are used to compute failure probability, economic risk and societal risk. Hence, each risk point that defines these distributions is computed using one of the fragility curves shown in Figure 6 within the event tree of Figure 7. For each dam, when these risk results are sorted, the risk distribution shown in Figure 8 is obtained. As can be observed in these graphs, societal risks are higher for Dam B and Dam C (average values around $10^{-1}$ lives/year), while risk variations due to epistemic uncertainty are higher for Dam A and Dam D (more than 4 orders of magnitude between upper and lower values).

Thirdly, once these risk distributions are obtained, Indexes of Coincidence proposed and described in this paper are computed to solve the key question of this paper: Is epistemic uncertainty influencing decision making?

With this purpose, the 20 risk reduction measures analyzed are prioritized following the procedure explained in [19], using the EWACSLS indicator [42], combining equity and efficiency principles. 

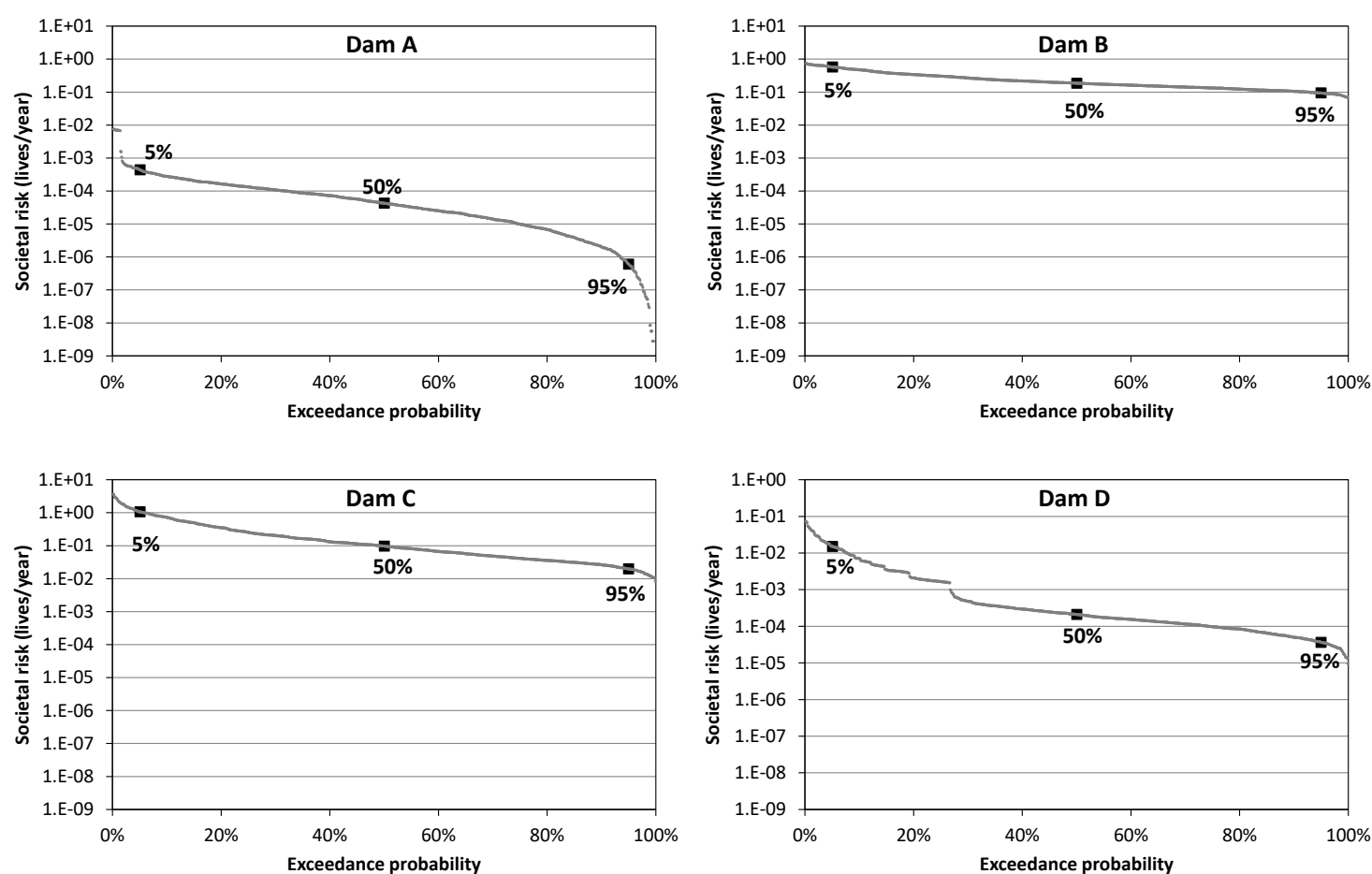

Figure 8: Societal risk probability distributions obtained for the four dams.

A reference implementation sequence of measures is obtained from the risk results, which in turn were obtained from the reference fragility curve in each dam. This reference sequences is obtained with average values without taking into account epistemic uncertainty. Next, 1000 implementation sequences were obtained combining the 1000 fragility curves with the risk results obtained for each dam. These 1000 sequences are compared with the reference sequence to obtain the average Indexes of Coincidence shown in Table 6. These indexes have been computed following the equations explained in Section 4. As can be observed in this table, these indexes have been computed after prioritizing measures for each dam independently and prioritizing the 20 measures together. Figure 9 shows the variation graphs of all sequences obtained for the prioritization of the 20 measures together.

\begin{tabular}{ccc}
\hline Dam & $\begin{array}{c}\text { Index of } \\
\text { Coincidence }\end{array}$ & $\begin{array}{c}\text { Adjusted Index of } \\
\text { Coincidence }\end{array}$ \\
\hline A & $99.35 \%$ & $99.29 \%$ \\
B & $79.86 \%$ & $69.55 \%$ \\
C & $87.42 \%$ & $86.97 \%$ \\
D & $94.11 \%$ & $90.77 \%$ \\
\hline All the dams & $86.95 \%$ & $86.60 \%$ \\
\hline
\end{tabular}

Table 6: Indexes of Coincidence obtained for the case study.

As can be observed, Indexes of Coincidence are lower for Dam B, which indicates that epistemic uncertainty has a higher influence on decision making, so uncertainty reduction actions are more recommended. In contrast, Indexes of Coincidence for Dam A are close to $100 \%$, which indicated that epistemic uncertainty has low influence on 
decision making. Indexes of Coincidence of Dams C and D indicate a medium influence of epistemic uncertainty on results.

These results are aligned with existing concerns of the dam manager about Dam B, due to the lack of knowledge about the resistance capacity of its foundation. In contrast, the foundation of Dam A is better characterized and the expected sliding failure risk is lower. In Dams $\mathrm{C}$ and $\mathrm{D}$, epistemic uncertainty about the dam foundation is substantially lower than in Dam B.

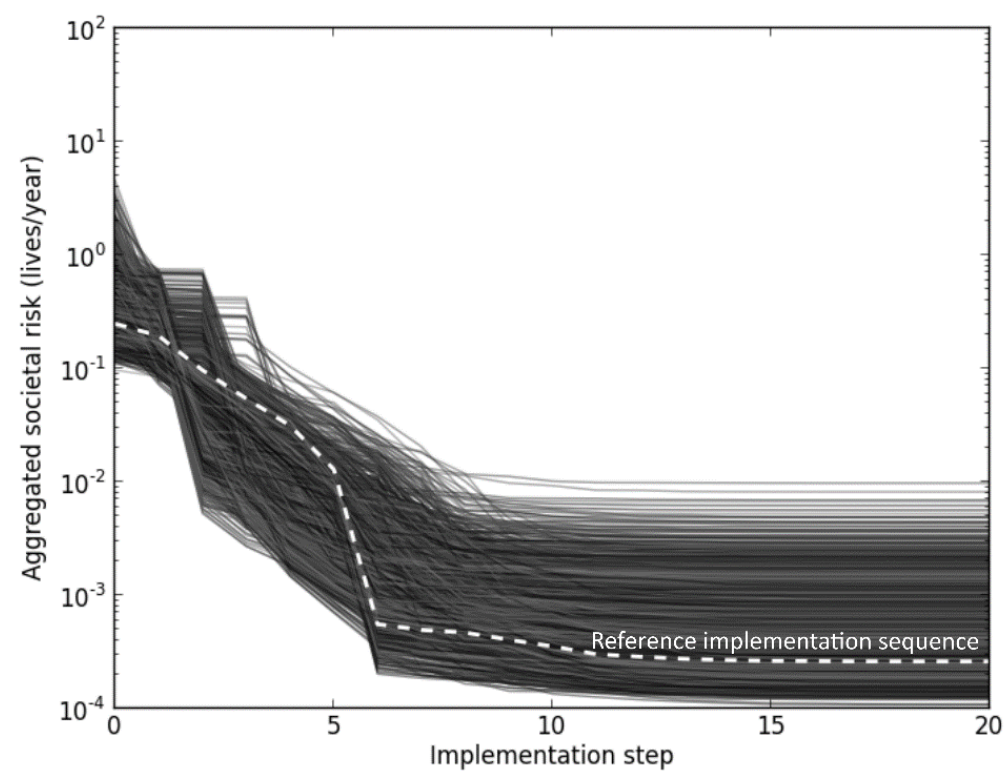

Figure 9: Variation graphs of the 1000 sequences obtained for the prioritization of the 20 measures together. $Y$ axis represents aggregated societal risk of the four dams.

In order to check if 1000 prioritization sequences are appropriate of more computations are needed, Figure 10 illustrates results based on the number of conducted computations. Indexes of Coincidence results are stable when the number of fragility curves is higher than 500. Hence, 1000 implementation sequences seems a valid decision.

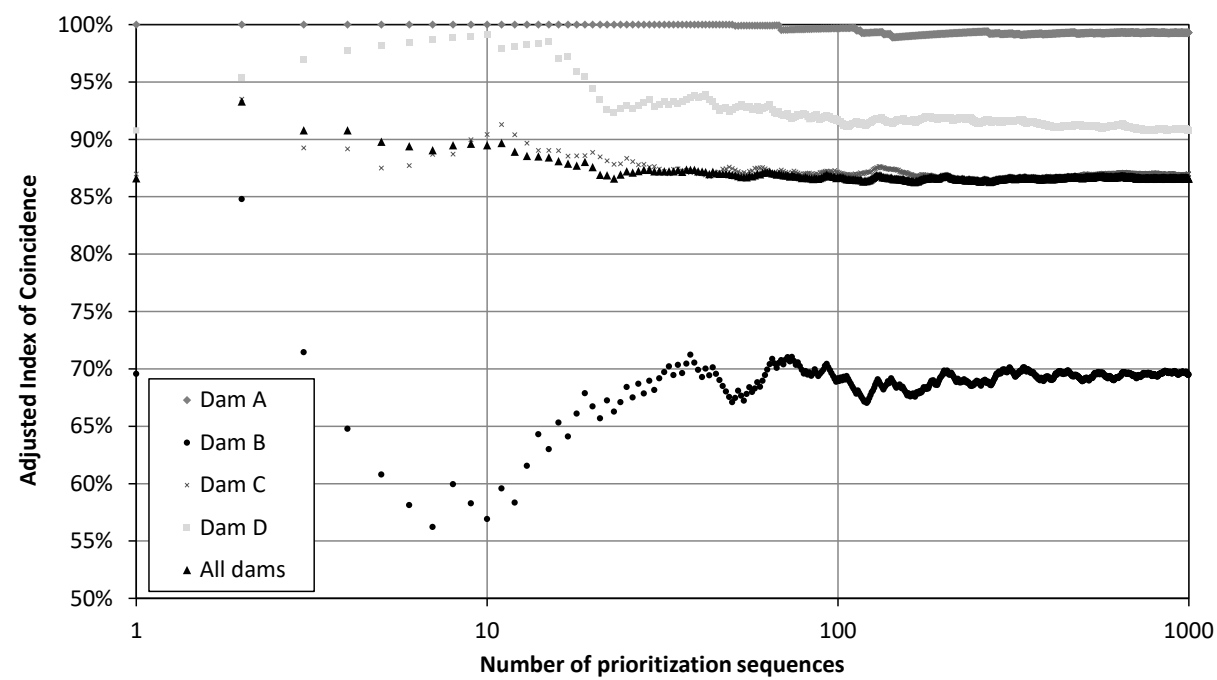

Figure 10: Influence of number of prioritization sequences in the Adjusted Indexes of Coincidence. 
Next, with the aim of analyzing the effect of the number of measures on the Indexes of Coincidence results, the analysis are repeated varying the number of measures from 5 to 20. In each case, the measures prioritized have been selected randomly from the 20 measures of the 4 dams. Results are shown in Figure 11. As expected, a clear correlation between the number of measures and the Indexes of Coincidence cannot be observed because of their formulation, since the number of measures is in the denominator.

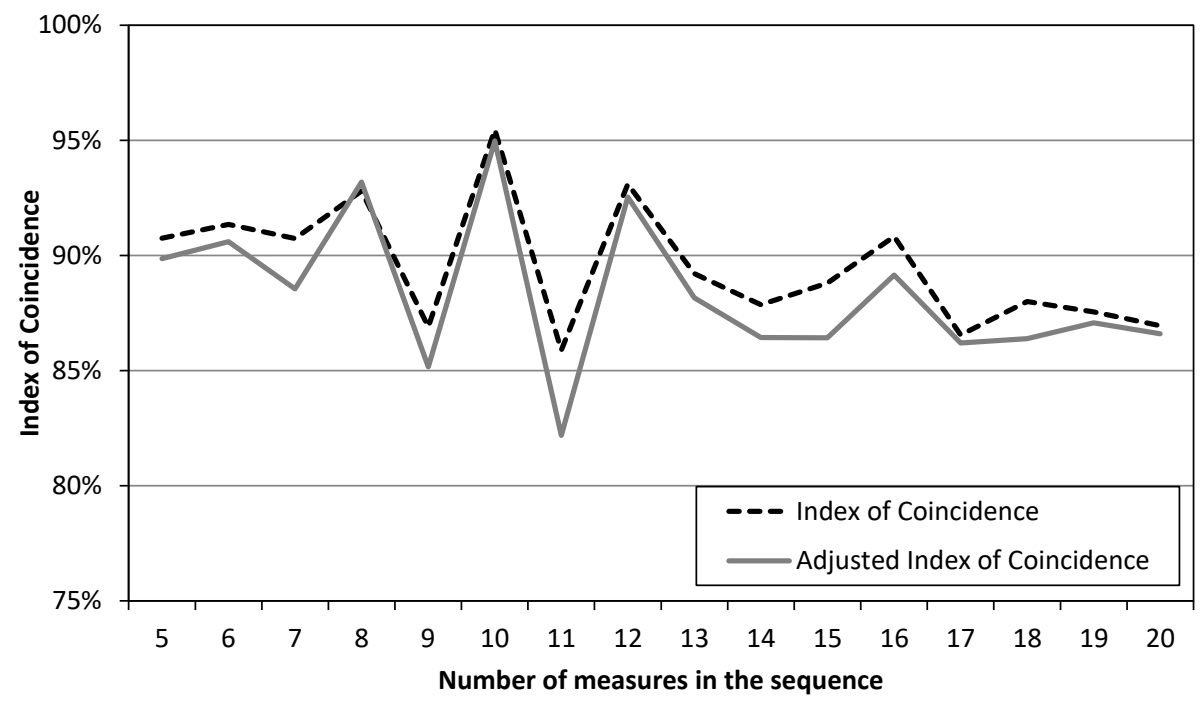

Figure 11: Variation of Indexes of Coincidence depending on the number of measures in the sequence.

Finally, the potential effect of epistemic uncertainty reduction measures for the foundation resistance capacity, like geotechnical tests and detailed surveys, are analyzed. With this purpose, the previous computations are repeated but reducing by half the standard deviation of the epistemic uncertainty probabilistic distributions shown in Table 5. In this case, the risk probability distributions shown in Figure 12 are obtained. It is obtained that reducing epistemic uncertainty has a direct effect in the steepness of probability distributions. 

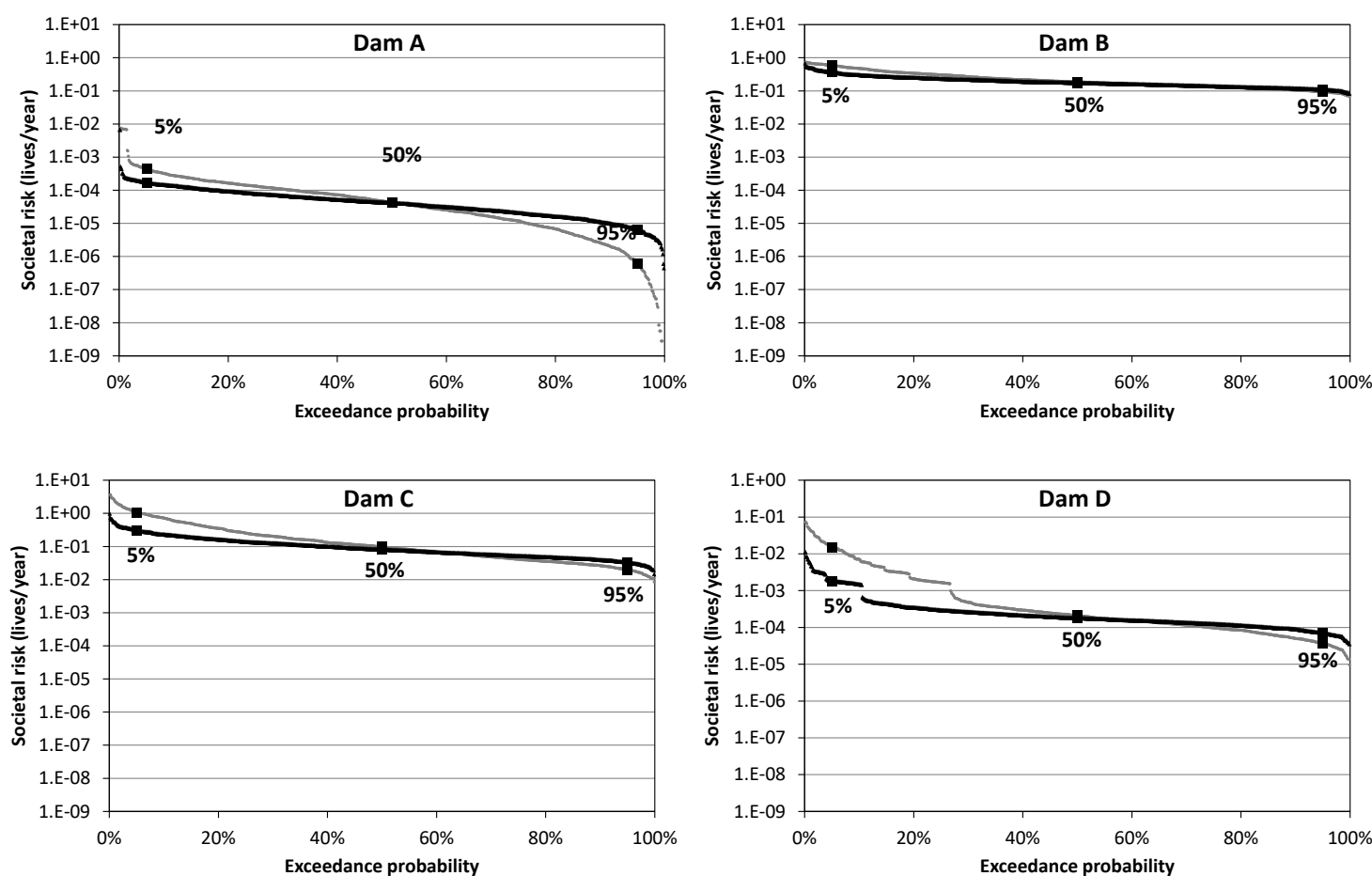

Figure 12: Societal risk probability distributions for all dams: base case (grey line) and after reducing epistemic uncertainty (black line).

Next, the same procedure is followed to obtain 1000 sequences of risk reduction measures for each dam individually and combining them. The itineraries for the combined case are shown in Figure 13. As expected, the spread of the itineraries is lower, although it does not mean that the measures are implemented in a different order that in Figure 9.

Thus, Indexes of Coincidence are recomputed for these cases as shown in Table 7. As can be observed the effect of reducing epistemic uncertainty in each dam is independently analyzed in the individual sequences of each dam and in the sequences obtained combining the four dams.

Results show that reducing epistemic uncertainty in Dam C and Dam D would have a higher influence in the decision making process for the whole system of dams. In contrast, the effect of reducing epistemic uncertainty in Dam A is lower. Epistemic uncertainty reduction in Dam B has a high effect in the sequences obtained for this dam individually but its effect in the management of the four dams together is more limited. Hence, epistemic reduction actions are recommended when this dam is individually managed, but from the combined management point of view, these actions would be more recommended in Dams C and D.

If the results of reducing globally epistemic uncertainty for the four dams are analyzed, it can be concluded that these actions could be useful to support a better risk-informed decision making, since they provide an increment of Indexes of Coincidence by $4 \%$. 


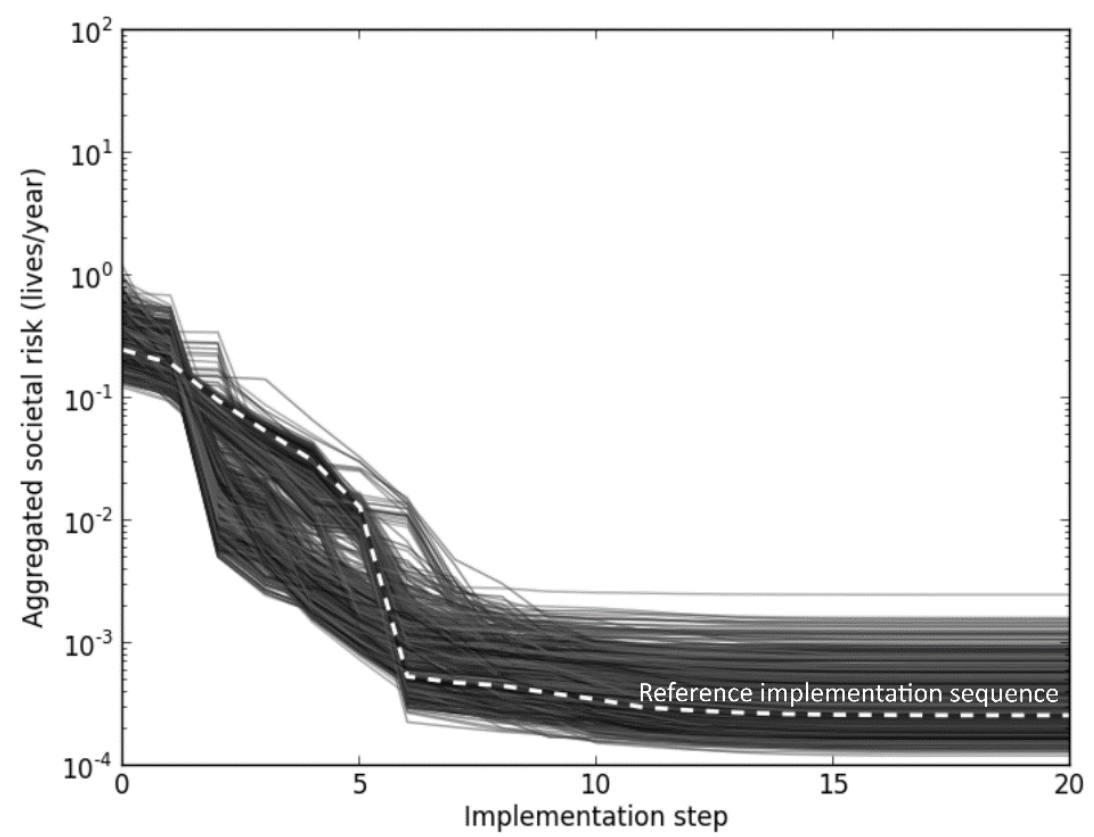

Figure 13: Variation graphs of the 1000 sequences obtained for the prioritization of the 20 measures after reducing epistemic uncertainty.

\begin{tabular}{ccccccc}
\hline \multicolumn{2}{c}{ Base case } & $\begin{array}{c}\text { Epistemic uncertainty } \\
\text { reduction }\end{array}$ & \multicolumn{2}{c}{ Difference } \\
\hline $\begin{array}{c}\text { Epistemic } \\
\text { uncertainty } \\
\text { reduction }\end{array}$ & $\begin{array}{c}\text { Index of } \\
\text { Coincidence }\end{array}$ & $\begin{array}{c}\text { Adjusted } \\
\text { Index of } \\
\text { Coincidence }\end{array}$ & $\begin{array}{c}\text { Index of } \\
\text { Coincidence }\end{array}$ & $\begin{array}{c}\text { Adjusted } \\
\text { Index of } \\
\text { Coincidence }\end{array}$ & $\begin{array}{c}\text { Index of } \\
\text { Coincidence }\end{array}$ & $\begin{array}{c}\text { Adjusted } \\
\text { Index of } \\
\text { Coincidence }\end{array}$ \\
\hline Ondy in Dam A & $99.35 \%$ & $99.29 \%$ & $99.94 \%$ & $99.94 \%$ & $0.60 \%$ & $0.66 \%$ \\
Only in Dam B & $79.86 \%$ & $69.55 \%$ & $83.19 \%$ & $74.55 \%$ & $3.34 \%$ & $5.00 \%$ \\
Only in Dam C & $87.42 \%$ & $86.97 \%$ & $89.38 \%$ & $89.57 \%$ & $1.96 \%$ & $2.60 \%$ \\
Only in Dam D & $94.11 \%$ & $90.77 \%$ & $96.74 \%$ & $94.55 \%$ & $2.63 \%$ & $3.78 \%$ \\
\hline Only in Dam A & $86.95 \%$ & $86.60 \%$ & $87.76 \%$ & $87.16 \%$ & $0.80 \%$ & $0.56 \%$ \\
Only in Dam B & $86.95 \%$ & $86.60 \%$ & $87.23 \%$ & $87.02 \%$ & $0.27 \%$ & $0.42 \%$ \\
Only in Dam C & $86.95 \%$ & $86.60 \%$ & $88.35 \%$ & $87.74 \%$ & $1.40 \%$ & $1.14 \%$ \\
Only in Dam D & $86.95 \%$ & $86.60 \%$ & $88.22 \%$ & $88.11 \%$ & $1.26 \%$ & $1.51 \%$ \\
\hline All dams & $86.95 \%$ & $86.60 \%$ & $91.28 \%$ & $90.68 \%$ & $4.33 \%$ & $4.08 \%$ \\
\hline
\end{tabular}

Table 7: Indexes of Coincidence: base case and after reducing epistemic uncertainty.

Finally, as can be observed in Table 6 and Table 7, both indexes provide very similar results, since changes in the first steps of the sequences usually result in changes also in the following steps, especially in sequences without a large number of measures. In any case, the adjusted index is considered to be more complete for the purpose of informing dam safety management since it gives more importance to the coincidence in the measures selected in the first steps of the sequence. 


\section{DISCUSSION}

After applying the proposed indexes of coincidence in the case study, the main identified discussion points regarding this procedure are:

- The case study introduced is focused on one source of uncertainty within the risk model: foundation resistant capacity. This approach of analyzing each source of epistemic uncertainty separately is more recommended since it provides a better understanding of what type of epistemic reduction actions are more effective.

- In any case, if epistemic uncertainty is included in more nodes of the model as explained in Section 2 and using existing propagation techniques of uncertainty, Indexes of Coincidence can also be obtained although they will be lower, since the effect of different sources of epistemic uncertainty is combined.

- Hence, the introduced case study is focused on epistemic uncertainties in the second term of the risk equation: the system response, but Indexes of Coincidence can also be used to analyze the effect of epistemic uncertainty in the other terms: loads probability and consequences.

- Based on the case study results, Indexes of Coincidence should also be computed for each dam individually, not only for the whole portfolio of dams. These Indexes of Coincidence are useful to identify how epistemic uncertainty is influencing decision making in each dam.

- In the case study, only one failure mode has been addressed (sliding) although in more complex cases, different failure modes could be combined. In these cases, epistemic uncertainties on the predominant failure modes will have a higher influence on decision making.

- Even though the introduced metrics in this paper are based on risk prioritization sequences obtained with risk reduction indicators, they could also be used to compare the influence of epistemic uncertainty in other types of measures prioritization sequences based on risk results.

- The effect on Indexes of Coincidence on risk reduction measures which also help to reduce epistemic uncertainty could be analyzed in future research. For example, improvements in the surveillance and monitoring system, since they help to detect the occurrence of failure modes and to increase the knowledge of the dam behavior.

- Separating epistemic uncertainty in risk models and analyzing its effect in decision making is very useful to properly inform decision making in fields with important uncertainties, like environment management and civil engineering. The proposed indexes analyze when investments should be made in reducing uncertainty prior to large structural works. For instance, the proposed frameworks and metrics could be used to indicate when more hydrological data is needed before deciding on new flood protection structural actions or when more geotechnical data is needed before spending money in rehabilitating an old bridge.

- In future research, epistemic uncertainty could be analyzed in different future scenarios (climate change, variation in the downstream population...) to inform dam safety management in the long term and to analyze how risk results evolve with time. 


\section{CONCLUSIONS}

Dams are located in a natural and heterogeneous environment that cannot be characterized exactly. For this reason, which is not shared by most other industries, dam safety governance deals with higher natural and epistemic uncertainties. Consequently, epistemic uncertainty may have a higher effect on decision making which highlights the importance of addressing it.

This paper introduces new metrics to analyze the influence of epistemic uncertainty in decision making for dam safety. This process is based on the results of a second-order probabilistic risk analysis, which requires separating natural and epistemic uncertainty within the risk model input data. Although this is not the most common approach in the dam safety field, the distinction between both types of uncertainty takes added importance for a proper dam safety management.

These metrics are computed by combining results of a second-order probabilistic risk analysis and prioritization of investments based on risk reduction indicators. Current approaches to deal with epistemic uncertainty are mainly focused on analyzing how uncertainty is propagated through risk models and results. However, indexes of coincidence go a step further by analyzing the influence of variations in risk results on decision making.

They have significant advantages to inform dam safety governance, since they allow to measure the effect of epistemic uncertainty in decision making. Hence, they help to identify needs for reducing gaps in dam knowledge, giving value to measures that do not have a direct effect on average risk results.

Although Indexes of Coincidence have been developed within the dam safety management field, they could be also applied for decision making in other fields with high epistemic uncertainty like environmental and civil engineering. The concepts behind these indexes are equally appropriate for other critical infrastructures, especially when epistemic uncertainty is very high.

Finally, it should be highlighted that the intent of the authors is to deal with uncertainty, rather than to fight against it, which is identified as one of the main elements of "smart governance" [47].

As in words of [47], "All knowledge is constructed and contingent. It is, figuratively speaking, a thin layer of ice over a deep ocean filled with non-knowledge and contingent knowledge connected to contingent forms of no-knowledge. People walk on this ice, and some even dance, celebrating their splendid assets of knowledge. (. . . )" and "uncertainty is neither a menace nor a weakness but should be treated instead as a normal condition of complex decision making and governance. The task then is to find efficient ways to cope with uncertainty without destroying uncertainty's invigorating dynamic". 


\section{REFERENCES}

[1] ICOLD, Risk assessment in dam safety management. A reconnaissance of benefits, methods and current applications. International Commission on Large Dams. Committee on dam safety. Bulletin 130. Paris: International Commission on Large Dams. Committee on dam safety. Bulletin 130, 2005.

[2] ANCOLD, Guidelines on Risk Assessment. Hobart: Australian National Committee on Large Dams, 2003.

[3] SPANCOLD, Risk analysis as applied to dam safety. Technical Guide on Operation of Dams and Reservoirs, vol. 1. Madrid: Professional Association of Civil Engineers. Spanish National Committee on Large Dams, 2012.

[4] USACE, "Safety of dams - Policy and procedures. Engineering and design. United States Army Corps of Engineers." United States Army Corps of Engineers, Washington D.C., 2014.

[5] HSE, "Reducing risks, protecting people - HSE's decision-making process. Health and Safety Executive." Sudbury, 2001.

[6] J. Jaffe and R. N. Stavins, "On the value of formal assessment of uncertainty in regulatory analysis," Regul. Gov., vol. 1, no. February, pp. 154-171, 2007.

[7] T. Bedford, "Decision Making for Group Risk Reduction: Dealing with Epistemic Uncertainty," Risk Anal., vol. 33, no. 10, pp. 1884-1898, 2013.

[8] F. O. Hoffman and J. S. Hammonds, "Propagation of Uncertainty in Risk Assessments: The Need to Distinguish Between Uncertainty Due to Lack of Knowledge and Uncertainty Due to Variability," Risk Anal., vol. 14, no. 5, pp. 707-712, Oct. 1994.

[9] S. Ferson and L. R. Ginzburg, "Different methods are needed to propagate ignorance and variability," Reliab. Eng. Syst. Saf., vol. 54, no. 2-3, pp. 133-144, 1996.

[10] D. N. D. Hartford and G. B. Baecher, Risk and Uncertainty in Dam Safety. Thomas Telford, 2004.

[11] J. Mullins, Y. Ling, S. Mahadevan, L. Sun, and A. Strachan, "Separation of aleatory and epistemic uncertainty in probabilistic model validation," Reliab. Eng. Syst. Saf., vol. 147, pp. 49-59, 2016.

[12] T. Aven and E. Zio, "Some considerations on the treatment of uncertainties in risk assessment for practical decision making," Reliab. Eng. Syst. Saf., vol. 96, no. 1, pp. 64-74, 2011.

[13] R. Kennedy and M. K. Ravindra, "Seismic fragilities for nuclear power plant risk studies," Nucl. Eng. Des., vol. 79, no. 1, pp. 47-68, 1984. 
[14] EPRI, "Methodology for Developing Seismic Fragilities. Electric Power Research Institute," 1994.

[15] V. M. Bier and S.-W. Lin, "On the Treatment of Uncertainty and Variability in Making Decisions About Risk,” Risk Anal., vol. 33, no. 10, pp. 1899-1907, 2013.

[16] D. Bolster et al., "Probabilistic risk analysis of groundwater remediation strategies," Water Resour. Res., vol. 45, no. 6, pp. 1-10, 2009.

[17] I. M. Khadam and J. J. Kaluarachchi, "Multi-criteria decision analysis with probabilistic risk assessment for the management of contaminated ground water," Environ. Impact Assess. Rev., vol. 23, pp. 683-721, 2003.

[18] M. H. C. Everdij, H. A. P. Blom, and S. H. Stroeve, "Structured assessment of bias and uncertainty in monte carlo simulated accident risk," no. September. National Aerospace Laboratory NLR, 2006.

[19] A. Morales-Torres, A. Serrano-Lombillo, I. Escuder-Bueno, and L. AltarejosGarcía, "The suitability of risk reduction indicators to inform dam safety management," Struct. Infrastruct. Eng., vol. 12, no. 11, pp. 1465-1476, 2016.

[20] S. Kaplan, "The words of risk analysis," Risk Anal., vol. 17, no. 4, pp. 407-417, 1997.

[21] L. Altarejos-García, I. Escuder-Bueno, A. Serrano-Lombillo, and M. G. de Membrillera-Ortuño, "Methodology for estimating the probability of failure by sliding in concrete gravity dams in the context of risk analysis," Struct. Saf., vol. 36-37, pp. 1-13, 2012.

[22] USBR and USACE, "Best Practices in Dam And Levee Safety Risk Analysis. United States Bureau of Reclamation and United States Army Corps of Engineers," United States Bureau of Reclamation and United States Army Corps of Engineers, Denver, 2015.

[23] A. Morales-Torres, I. Escuder-Bueno, L. Altarejos-García, and A. SerranoLombillo, "Building fragility curves of sliding failure of concrete gravity dams integrating natural and epistemic uncertainties," Eng. Struct., vol. 125, pp. 227$235,2016$.

[24] E. Paté-Cornell, "Risk and uncertainty analysis in government safety decisions," Risk Anal., vol. 22, no. 3, pp. 633-646, 2002.

[25] J. K. Vrijling and P. H. A. J. M. van Gelder, "Societal risk and the concept of risk aversion," in Advances in safety and reliability, vol. 1, C. Guedes Soares, Ed. Oxford: Elsevier Science, 1997, pp. 45-52.

[26] M. E. Paté-Cornell, "Uncertainties in risk analysis: Six levels of treatment," Reliab. Eng. Syst. Saf., vol. 54, no. 2-3, pp. 95-111, 1996. 
[27] P. Baraldi and E. Zio, "A Combined Monte Carlo and possibilistic approach to uncertainty propagation in event tree analysis," Risk Anal., vol. 28, no. 5, pp. 1309-1325, 2008.

[28] S. S. Chauhan and D. S. Bowles, "Incorporating uncertainty into dam safety risk assessment," in Proceedings of Risk Analysis in Dam Safety, 2001.

[29] V. Vasconcelos, W. Soares, A. C. Costa, and A. Raso, "Treatment of Uncertainties in Probabilistic Risk Assessment," 2019, p. 1 to 17.

[30] S. Rahman, D. R. Karanki, A. Epiney, D. Wicaksono, O. Zerkak, and V. N. Dang, "Deterministic sampling for propagating epistemic and aleatory uncertainty in dynamic event tree analysis," Reliab. Eng. Syst. Saf., vol. 175, no. April 2017, pp. 62-78, 2018.

[31] S. Nannapaneni and S. Mahadevan, "Reliability analysis under epistemic uncertainty," Reliab. Eng. Syst. Saf., vol. 155, pp. 9-20, 2016.

[32] H. Thorisson, J. H. Lambert, J. J. Cardenas, and I. Linkov, "Resilience Analytics with Application to Power Grid of a Developing Region," Risk Anal., vol. 37, no. 7, pp. 1268-1286, 2017.

[33] C. Carvajal, L. Peyras, P. Arnaud, D. Boissier, and P. Royet, "Probabilistic Modeling of Floodwater Level for Dam Reservoirs," J. Hydrol. Eng., vol. 14, no. 3, pp. 223-232, 2009.

[34] A. Serrano-Lombillo, J. Fluixá-Sanmartín, and V. J. Espert-Canet, "Flood routing studies in risk analysis," in Risk Analysis, Dam Safety, Dam Security and Critical Infrastructure Management, vol. Valencia, I. Escuder-Bueno, E. Matheu, L. Altarejos-García, and J. T. Castillo-Rodríguez, Eds. Leiden: CRC Press, 2012, pp. 99-105.

[35] H. Apel, a. H. Thieken, B. Merz, and G. Blöschl, "Flood risk assessment and associated uncertainty," Nat. Hazards Earth Syst. Sci., vol. 4, no. 2, pp. 295-308, 2004.

[36] P. Bianucci, A. Sordo-Ward, J. I. Pérez, J. García-Palacios, L. Mediero, and L. Garrote, "Risk-based methodology for parameter calibration of a reservoir flood control model," Nat. Hazards Earth Syst. Sci., vol. 13, no. 4, pp. 965-981, 2013.

[37] S. Chauhan and D. Bowles, "Incorporating uncertainty into dam safety risk assessment," in Proceedings of Risk Analysis in Dam Safety, 2001.

[38] L. Altarejos-García, F. Silva-Tulla, I. Escuder-Bueno, and A. Morales-Torres, "Practical risk assessment for embankments, dams, and slopes," in Risk and Reliability in Geotechnical Engineering, K.-K. Phoon and J. Ching, Eds. Boca Raton: CRC Press, 2014, pp. 437-469.

[39] L. Altarejos-García, M. L. Martínez-Chenoll, I. Escuder-Bueno, and A. Serrano- 
Lombillo, "Assessing the impact of uncertainty on flood risk estimates with reliability analysis using 1-D and 2-D hydraulic models," Hydrol. Earth Syst. Sci., vol. 16, no. 7, pp. 1895-1914, 2012.

[40] M. Aboelata, D. S. Bowles, and D. M. McClelland, "A model for estimating dam failure life loss," in Proceedings of the Australian Committee on Large Dams Risk Workshop, 2003, no. October.

[41] USBR, Dam Safety Public Protection Guidelines - A Risk Framework to Support Dam Safety Decision-Making, no. August. United States Bureau of Reclamation, 2011.

[42] A. Serrano-Lombillo, A. Morales-Torres, I. Escuder-Bueno, and L. AltarejosGarcía, "A new risk reduction indicator for dam safety management combining efficiency and equity principles," Struct. Infrastruct. Eng., 2016.

[43] W. F. Friedman, The index of Coincidence and its applications in cryptanalysis. 1987.

[44] ICOLD, Dam failures - Statistical analysis. Bulletin 99. International Commission on Large Dams. International Commission on Large Dams, 1995.

[45] iPresas, "iPresas calc. User guide.” iPresas Risk Analysis, Valencia, 2016.

[46] A. Serrano-Lombillo, A. Morales-Torres, and L. A. García-Kabbabe, "Consequence estimation in risk analysis," in Risk Analysis, Dam Safety, Dam Security and Critical Infrastructure Management, I. Escuder-Bueno, E. Matheu, L. Altarejos-García, and J. T. Castillo-Rodríguez, Eds. Leiden: CRC Press, 2012, pp. 107-112.

[47] H. Willke, Smart Governance: Governing the Global Knowledge Society. Campus Verlag, 2007. 